\title{
ANALISIS DAMPAK KEBISINGAN TERHADAP KOMUNIKASI DAN KONSENTRASI BELAJAR SISWA SEKOLAH PADA JALAN PADAT LALU LINTAS
}

Moehammad Riyan Zikri ${ }^{11}$, Dian Rahayu Jati, ST, M.Si. ${ }^{2)}$, S. Nurlaily Kadarini, ST, MT. ${ }^{3)}$

1).Program Studi Teknik Lingkungan Jurusan Teknik Sipil Fakultas Teknik Universitas Tanjungpura, Pontianak 2) Program Studi Teknik Sipil Jurusan Teknik Sipil Fakultas Teknik Universitas Tanjungpura, Pontianak Email: ryan.zikri22@gmail.com

\begin{abstract}
ABSTRAK
Kebisingan adalah salah satu jenis polusi yang berpengaruh terhadap lingkungan. Salah satu sumber polusi suara adalah kebisingan yang berasal dari jalan padat lalu lintas. Penelitian ini bertujuan untuk mengetahui tingkat kebisingan di MTsN 1 Pontianak di Jalan Alianyang serta mengetahui pengaruh kebisingan terhadap komunikasi dan konsentrasi belajar siswa di sekolah tersebut kemudian memperkirakan upaya yang dapat dilakukan untuk meminimalkan dampak kebisingan bagi para siswa. Waktu pengukuran adalah pada range jam 06.30-09.00 dan 10.0013.00 WIB dengan menggunakan Sound Level Meter. Pemilihan jam pengukuran kebisingan berdasarkan laporan Penyusunan Tataran Transportasi Lokal Kota Pontianak tahun 2012 oleh Dinas Perhubungan Komunikasi dan Informatika dan disesuaikan dengan jam saat masuk kelas yaitu pada saat masuk sekolah dan jam masuk kelas setelah istirahat. Pengukuran dampak kebisingan terhadap komunikasi dan konsentrasi belajar siswa dalam penelitian ini menggunakan kuesioner sebanyak 90 lembar yang dibagikan merata pada tiap kelas. Tingkat kebisingan pada MTsN 1 Pontianak melebihi ambang batas kebisingan untuk sekolah yaitu sebesar $55 \mathrm{~dB}$. Tingkat kebisingan terbesar pada Jalan Alianyang adalah $74.2 \mathrm{~dB}$, sedangkan pada halaman sekolah sebesar 66,6 dB. Dari analisis kuesioner, 96\% siswa menyatakan bahwa sekolah tersebut bising, dan $89 \%$ responden menyatakan kebisingan dari lalu lintas mengganggu konsentrasi mereka dalam proses belajar mengajar di kelas. Dari analisis prestasi belajar siswa kelas 8 dan 9 yang mengalami penurunan sebanyak $62,5 \%$. Upaya penanganan untuk mengurangi tingkat kebisingan adalah dengan menanam pepohonan di depan sekolah, membuat barrier kebisingan pada sekolah, membuat marka jalan dan rambu lalu lintas, serta ruangan kelas yang dapat dibuat lebih kedap suara dengan menambahkan bahan peredam sehingga kebisingan tidak masuk dan mengganggu proses belajar mengajar di kelas.
\end{abstract}

Kata kunci : Kebisingan di Sekolah, Konsentrasi, Gangguan Komunikasi.

\section{ABSTRACT}

Noise is one of the pollution that has effect to environtment. One of the source of sound pollution is noise from traffic. This study aims to determine the level of noise in MTsN 1 Pontianak on Alianyang Street as well as determine the effect of noise on communication and concentration of student learning at the school and then estimate the effort that can be done to minimize the noise impact for the students. Time measurement is in the range of 6.30 to 09.00 WIB and 10.00 to 13.00 WIB by using Sound Level Meter. Selection of timing noise measurement is based on the level of Penyusunan Tataran Transportasi Lokal Kota Pontianak report in 2012 by the Department of Transportation, Communication and Information and adjusted to the hours when entering the classroom is at the time of school entry and hours go to class after the break. Measuring the impact of noise on communication and concentration of students in this study used a questionnaire as many as 90 sheets distributed evenly on each class. The noise level at MTsN 1 Pontianak exceeds the threshold of noise for the school that is equal to $55 \mathrm{~dB}$. The biggest noise level was $74.2 \mathrm{~dB}$ at Alianyang Street, while on the school yard at $66.6 \mathrm{~dB}$. From the analysis of learning achievement, $96 \%$ of students stated that the school is noisy, and $89 \%$ of respondents said the noise from traffic disturb their concentration in learning in the classroom. From the analysis of the 8th and 9th grade students who decreased learning achievements are $62.5 \%$ of students stated that noisy conditions also affect the value as well as their achievements. Handling efforts to reduce the noise level is to plant trees in front of the school, making noise barrier at the school, making road markings and traffic signs, as well as classrooms that can be 
made more soundproof by adding damping material so that the noise did not go in and interfere with the learning process in the classroom.

Keywords: Noise at School, Concentration, Communication Disorders.

\section{PENDAHULUAN}

Proses pendidikan umumnya terjadi di sekolah. Lokasi dan kondisi di sekitar sekolah memiliki peran penting dalam berlangsungnya proses belajar mengajar. Hal tersebut seharusnya dapat memberikan dukungan terhadap proses pendidikan agar kegiatan belajar mengajar terjadi dengan baik. Saat ini banyak lokasi sekolah yang terletak di pinggir jalan raya karena sulitnya menemukan lahan yang tepat untuk mendirikan sekolah akibat pembangunan yang berkembang dengan cepat seiring dengan pertumbuhan penduduk. Pertumbuhan penduduk juga memicu bertambahnya jumlah kendaraan bermotor. Sehingga sekolah-sekolah yang terletak di pinggir jalan raya tersebut terkena dampak dari peningkatan jumlah kendaraan bermotor salah satunya adalah kebisingan. Kebisingan tentunya dapat berdampak tidak baik terhadap proses belajar mengajar hingga konsentrasi siswa di sekolah tersebut.

Dalam penelitian ini dilakukan analisis dampak kebisingan terhadap siswa sekolah yang terdapat pada Jalan Alianyang Kota Pontianak karena derajat kepadatan lalu lintas ( $\mathrm{v} / \mathrm{c}$ ratio) di jalan tersebut cukup besar. Penelitian ini menganalisis dampak kebisingan bagi komunikasi dan konsentrasi yang dialami siswa di sekolah pada Jalan Alianyang yaitu siswa MTs Negeri 1 Pontianak. Alasan pemilihan sekolah ini adalah karena MTs Negeri 1 Pontianak lokasinya langsung menghadap ke jalan dan tidak terhalang bangunan lain juga kurangnya tanaman yang berada di depan sekolah sehingga kebisingan dari lalu lintas langsung dirasakan oleh siswa sekolah tersebut.

Penelitian ini bertujuan untuk mengetahui tingkat kebisingan di MTsN 1 Pontianak di Jalan Alianyang serta mengetahui pengaruh kebisingan terhadap komunikasi dan konsentrasi belajar siswa di sekolah tersebut kemudian memperkirakan upaya yang dapat dilakukan untuk meminimalkan dampak kebisingan bagi para siswa.

\section{METODE PENELITIAN}

\section{A. TEMPAT DAN WAKTU PENGAMBILAN SAMPEL}

Penelitian ini dilakukan di MTsN 1 Pontianak yang terletak di Jalan Alianyang Kota Pontianak. Lokasi pengambilan sampel kebisingan terbagi menjadi beberapa titik yaitu di tepi Jalan Alianyang, di halaman sekolah MTsN 1 Pontianak, di luar kelas dan di dalam kelas pada tiap lantai. Penelitian ini dilaksanakan pada hari kerja, yaitu hari Selasa tanggal 16 September 2014. Pada jam masuk hingga pulang sekolah yaitu, pukul 06.30-13.00 WIB. Kemudian jam ini dibagi menjadi 2 sesi yaitu pada jam pagi 06.30-09.00 WIB dan jam siang 10.00-13.00 WIB.

\section{B. METODE PENGUMPULAN DATA}

Metode pengumpulan data pada penelitian ini antara lain sebagai berikut:

a. Jarak, dalam penelitian ini diukur jarak antara jalan raya dengan bangunan kelas dengan jalan raya menggunakan meteran. Tujuan dilakukan pengukuran jarak adalah untuk mengetahui jarak antara jalan dengan bangunan sekolah dan kelas.

b. Kebisingan, dalam penelitian ini pengukuran kebisingan dilakukan di depan dan di dalam masing-masing kelas, di tepi jalan raya dan di tengah halaman sekolah. Waktu pengukuran adalah pada range jam 06.30-09.00 WIB dan 10.00-13.00 WIB dengan menggunakan Sound Level Meter. Pemilihan jam pengukuran kebisingan berdasarkan laporan Penyusunan Tataran Transportasi Lokal Kota Pontianak tahun 2012 oleh Dinas Perhubungan Komunikasi dan Informatika dan disesuaikan dengan jam saat masuk kelas yaitu pada saat masuk sekolah dan jam masuk kelas setelah istirahat.

c. Kuesioner, dalam penelitian ini pengukuran dampak kebisingan terhadap komunikasi dan konsentrasi menggunakan kuesioner yang dibagikan kepada siswa. Data yang didapat dari lembar kuesioner yaitu nama, usia, jenis kelamin, kelas dan keluhan dampak kebisingan. 


\section{ANALISA DATA}

Berdasarkan rumusan masalah dan tujuan penelitian, maka analisa data yang digunakan dalam penelitian ini yaitu:

1. Untuk mengetahui tingkat kebisingan pada MTsN 1 Pontianak, digunakan metode statistik deskriptif.

2. Untuk mengetahui pengaruh kebisingan terhadap komunikasi dan konsentrasi siswa digunakan hasil analisis kuesioner menggunakan software Microsoft Excel dimana didapat presentase gangguan kebisingan serta gangguan komunikasi dan konsentrasi yang dialami siswa. Kemudian hasil tersebut dihubungkan dengan hasil pengukuran kebisingan di MTsN 1 Pontianak.

\section{HASIL DAN PEMBAHASAN}

\section{A. KARAKTERISTIK RESPONDEN}

Dari jumlah sampel diatas, pada masing-masing kelas diambil jumlah responden sama rata yaitu 5 orang tiap kelas.

1) Umur

Dibawah ini adalah tabel distribusi umur responden siswa MTsN 1 Pontianak.

Tabel 1. Tabel Distribusi Umur Responden

\begin{tabular}{|c|c|c|c|c|c|c|}
\hline \multirow{2}{*}{ Kelas } & \multicolumn{5}{|c|}{ Umur } & \multirow{2}{*}{ Total } \\
\cline { 2 - 6 } & 11 & 12 & 13 & 14 & 15 & \\
\hline VII & 2 & 22 & 6 & 0 & 0 & 30 \\
\hline VIII & 0 & 3 & 21 & 6 & 0 & 30 \\
\hline IX & 0 & 0 & 8 & 21 & 1 & 30 \\
\hline Total & 2 & 25 & 35 & 27 & 1 & 90 \\
\hline
\end{tabular}

Sumber: Hasil Analisis Kuesioner, 2014

Berdasarkan tabel 1 diatas didapat umur siswa paling muda adalah 11 tahun yang terdapat di kelas VII dan tertua adalah 15 tahun terdapat pada kelas IX.

2) Jenis Kelamin

Berikut adalah tabel yang menunjukan distribusi jenis kelamin responden siswa MTsN 1 Pontianak.

Tabel 2. Tabel Distribusi Jenis Kelamin Responden

\begin{tabular}{|c|c|c|c|}
\hline \multirow{2}{*}{ Kelas } & \multicolumn{2}{|c|}{ Jenis Kelamin } & \multirow{2}{*}{ Total } \\
\cline { 2 - 3 } & Laki-Laki & Perempuan & \\
\hline VII & 11 & 19 & 30 \\
\hline VIII & 18 & 12 & 30 \\
\hline IX & 16 & 14 & 30 \\
\hline Total & 45 & 45 & 90 \\
\hline
\end{tabular}

Sumber: Hasil Analisis Kuesioner, 2014

Dari tabel 2 diatas dapat dilihat jumlah jenis kelamin antara laki-laki dan perempuan berjumlah sama yaitu 45 orang.

\section{3) KARAKTERISTIK SEKOLAH}

Dalam penelitian ini MTsN 1 Pontianak dijadikan lokasi penelitian karena lokasi sekolah yang berada tepat di tepi jalan padat lalu lintas dan bangunan sekolah yang berbentuk $U$ sehingga tidak terhalang bangunan lain. Vegetasi yang terdapat di depan sekolah juga tergolong sangat minim, hanya terdapat beberapa pohon yang tidak rindang serta semak yang berada dekat dengan pagar sekolah dimana pagar tersebut juga tidak terlalu tinggi. 
Jarak antara Jalan Alianyang dengan bangunan sekolah yang terdekat adalah 22,6m sedangkan dengan bangunan yang terjauh adalah $47,9 \mathrm{~m}$. Berikut ini adalah denah kelas pada lantai 1 MTs Negeri 1 Pontianak.

\section{4) ANALISIS TINGKAT KEBISINGAN PADA JALAN ALIANYANG DAN HALAMAN SEKOLAH}

Berdasarkan pengukuran kebisingan yang dilakukan di Madrasah Tsanawiyah 1 Pontianak didapatkan tingkat kebisingan di Jalan Alianyang dan di halaman MTsN 1 Pontianak. Tingkat kebisingan tersebut dapat dilihat pada tabel 3 dibawah ini.

Tabel 3. Tingkat Kebisingan pada Jalan Alianyang dan Halaman Sekolah

\begin{tabular}{|c|c|c|}
\hline \multirow{2}{*}{ Kelas } & \multicolumn{2}{|c|}{ Waktu Pengukuran } \\
\cline { 2 - 3 } & $06.30-09.00$ & $10.00-13.00$ \\
\hline Jalan Alianyang & $74,2 \mathrm{~dB}$ & $68,5 \mathrm{~dB}$ \\
\hline Halaman Sekolah & $66,6 \mathrm{~dB}$ & $61,4 \mathrm{~dB}$ \\
\hline
\end{tabular}

Sumber: Hasil Analisis, 2014

Dari hasil pengukuran kebisingan tersebut dapat dilihat bahwa tingkat kebisingan pada jam 06.30-09.00 WIB maupun pada jam 10.00-13.00 WIB melebihi ambang batas kebisingan untuk sekolah dalam Keputusan Menteri Lingkungan Hidup no. Kep-48/MENLH/11/1996 yaitu sebesar $55 \mathrm{~dB}$. Tingkat kebisingan yang melebihi ambang batas kebisingan disebabkan karena jumlah kendaraan yang melewati Jalan Alianyang cukup padat terutama pada jam 06.30-09.00 WIB.

\section{5) ANALISIS KEBISINGAN DI KELAS}

Kebisingan juga diukur di kelas-kelas yang terdapat pada tiap lantai di sekolah tersebut. Pada tiap kelas dilakukan pengukuran kebisingan di dalam dan di luar kelas. Berikut ini adalah tabel tingkat kebisingan di lantai 1.

Tabel 4. Tingkat Kebisingan Pada Lantai 1

\begin{tabular}{|c|c|c|c|}
\hline \multirow{2}{*}{ Kelas } & \multirow{2}{*}{ Posisi } & \multicolumn{2}{|c|}{ Waktu Pengukuran } \\
\cline { 3 - 4 } & & $06.40-07.50$ & $10.00-11.10$ \\
\hline \multirow{2}{*}{$9 \mathrm{C}$} & Luar & $76,0 \mathrm{~dB}$ & $72,4 \mathrm{~dB}$ \\
\cline { 2 - 4 } & Dalam & $78,0 \mathrm{~dB}$ & $77,1 \mathrm{~dB}$ \\
\hline \multirow{2}{*}{$9 \mathrm{D}$} & Luar & $68,9 \mathrm{~dB}$ & $73,2 \mathrm{~dB}$ \\
\cline { 2 - 4 } & Dalam & $71,4 \mathrm{~dB}$ & $82,4 \mathrm{~dB}$ \\
\hline \multirow{2}{*}{$9 \mathrm{E}$} & Luar & $75,0 \mathrm{~dB}$ & $76,4 \mathrm{~dB}$ \\
\cline { 2 - 4 } & Dalam & $67,9 \mathrm{~dB}$ & $78,9 \mathrm{~dB}$ \\
\hline \multirow{2}{*}{$9 \mathrm{~F}$} & Luar & $72,0 \mathrm{~dB}$ & $66,7 \mathrm{~dB}$ \\
\cline { 2 - 4 } & Dalam & $76,7 \mathrm{~dB}$ & $72,5 \mathrm{~dB}$ \\
\hline
\end{tabular}

Sumber: Hasil Analisis, 2014

Dari tabel 4 diatas dapat dilihat bahwa tingkat kebisingan yang terukur di lantai 1 MTsN 1 Pontianak melebihi ambang batas kebisingan untuk sekolah dalam Keputusan Menteri Lingkungan Hidup no. Kep-48/MENLH/11/1996 yaitu sebesar 55 dB. Tingkat kebisingan tertinggi luar kelas pada lantai 1 terdapat di kelas $9 E$ yaitu sebesar 76,4 dB pada jam 10.0013.00 WIB. Hal ini disebabkan karena suara bising yang terdapat di belakang MTsN1 yaitu siswa SMK PGRI yang sedang melakukan aktifitas olahraga. Kemudian tingkat kebisingan tertinggi di dalam kelas terdapat pada kelas 9D yaitu sebesar $82,4 \mathrm{~dB}$ pada jam $10.00-13.00$ WIB. Hal ini disebabkan karena posisi kelas yang menghadap ke jalan raya dan juga suasana kelas yang tidak ada guru sehingga para murid berbicara dengan suara lantang sehingga tingkat kebisingan yang terukur sangat tinggi. 
Tingkat kebisingan di luar dan di dalam kelas pada lantai 2 dapat dilihat pada tabel berikut.

Tabel 5. Tingkat Kebisingan Pada Lantai 2

\begin{tabular}{|c|c|c|c|}
\hline \multirow{2}{*}{ Kelas } & \multirow{2}{*}{ Posisi } & \multicolumn{2}{|c|}{ Waktu Pengukuran } \\
\cline { 3 - 4 } & & $06.40-07.50$ & $10.00-11.10$ \\
\hline \multirow{2}{*}{$9 \mathrm{~B}$} & Luar & $68,6 \mathrm{~dB}$ & $78,5 \mathrm{~dB}$ \\
\cline { 2 - 4 } & Dalam & $72,1 \mathrm{~dB}$ & $62,1 \mathrm{~dB}$ \\
\hline \multirow{2}{*}{$8 \mathrm{C}$} & Luar & $70,4 \mathrm{~dB}$ & $72,2 \mathrm{~dB}$ \\
\cline { 2 - 4 } & Dalam & $82,9 \mathrm{~dB}$ & $78,2 \mathrm{~dB}$ \\
\hline \multirow{2}{*}{$8 \mathrm{D}$} & Luar & $69,7 \mathrm{~dB}$ & $74,2 \mathrm{~dB}$ \\
\cline { 2 - 4 } & Dalam & $72,9 \mathrm{~dB}$ & $77,0 \mathrm{~dB}$ \\
\cline { 2 - 4 } & Dalam & $70,1 \mathrm{~dB}$ & $70,7 \mathrm{~dB}$ \\
\hline \multirow{2}{*}{$8 \mathrm{E}$} & Luar & $69,1 \mathrm{~dB}$ & $69,8 \mathrm{~dB}$ \\
\cline { 2 - 4 } & Dalam & $70,0 \mathrm{~dB}$ & $78,7 \mathrm{~dB}$ \\
\hline \multirow{2}{*}{$8 \mathrm{~F}$} & Luar & $69,4 \mathrm{~dB}$ & $68,2 \mathrm{~dB}$ \\
\cline { 2 - 4 } & Dalam & $84,1 \mathrm{~dB}$ & $81,7 \mathrm{~dB}$ \\
\hline \multirow{2}{*}{$7 \mathrm{~F}$} & Luar & $71,8 \mathrm{~dB}$ & $62,8 \mathrm{~dB}$ \\
\hline & Dalam & $77,3 \mathrm{~dB}$ & $69,5 \mathrm{~dB}$ \\
\hline
\end{tabular}

Sumber: Hasil Analisis, 2014

Berdasarkan tabel 5 diatas dapat dilihat tingkat kebisingan pada luar kelas-kelas di lantai 2 MTsN 1. Tingkat kebisingan yang terukur di lantai 2 MTsN 1 Pontianak melebihi ambang batas kebisingan untuk sekolah dalam Keputusan Menteri Lingkungan Hidup no. Kep48/MENLH/11/1996 yaitu sebesar 55 dB. Kebisingan pada luar kelas yang tertinggi terdapat pada kelas 9B yaitu sebesar 78,5 dB pada jam 10.00-13.00 WIB. Hal ini disebabkan karena pada jam tersebut banyak siswa yang lalu lalang di depan kelas tersebut karena memasuki jam olahraga dan juga disebabkan posisi kelas yang menghadap langsung ke jalan raya tanpa terhalang bangunan lain. Kemudian kebisingan di dalam kelas yang tertinggi terdapat pada kelas 8D yaitu sebesar 93,1 dB pada jam 10.00-13.00 WIB. Hal ini disebabkan karena kondisi kelas yang sedang melakukan kegiatan tanya jawab sehingga para siswa menyebabkan kebisingan yang cukup besar.

Berikut adalah tabel tingkat kebisingan di luar dan di dalam kelas pada lantai 3 yang terukur. 
Tabel 6. Tingkat Kebisingan Pada Lantai 3

\begin{tabular}{|c|c|c|c|}
\hline \multirow{2}{*}{ Kelas } & \multirow{2}{*}{ Posisi } & \multicolumn{2}{|c|}{ Waktu Pengukuran } \\
\cline { 3 - 4 } & & $06.40-07.50$ & $10.00-11.10$ \\
\hline \multirow{2}{*}{$8 B$} & Luar & $70,1 \mathrm{~dB}$ & $66,7 \mathrm{~dB}$ \\
\cline { 2 - 4 } & Dalam & $73,3 \mathrm{~dB}$ & $68,1 \mathrm{~dB}$ \\
\hline \multirow{2}{*}{$8 \mathrm{~A}$} & Luar & $70,3 \mathrm{~dB}$ & $66,3 \mathrm{~dB}$ \\
\cline { 2 - 4 } & Dalam & $70,8 \mathrm{~dB}$ & $63,3 \mathrm{~dB}$ \\
\hline \multirow{2}{*}{ 7A } & Luar & $74,1 \mathrm{~dB}$ & $73,2 \mathrm{~dB}$ \\
\cline { 2 - 4 } & Dalam & $61,6 \mathrm{~dB}$ & $71,5 \mathrm{~dB}$ \\
\hline \multirow{2}{*}{ 7B } & Luar & $72,6 \mathrm{~dB}$ & $73,9 \mathrm{~dB}$ \\
\cline { 2 - 4 } & Dalam & $66,6 \mathrm{~dB}$ & $65,6 \mathrm{~dB}$ \\
\hline \multirow{2}{*}{ 7C } & Luar & $67,6 \mathrm{~dB}$ & $72,1 \mathrm{~dB}$ \\
\cline { 2 - 4 } & Dalam & $71,2 \mathrm{~dB}$ & $70,7 \mathrm{~dB}$ \\
\hline \multirow{2}{*}{ 7D } & Luar & $72,8 \mathrm{~dB}$ & $69,9 \mathrm{~dB}$ \\
\cline { 2 - 4 } & Dalam & $65,8 \mathrm{~dB}$ & $77,2 \mathrm{~dB}$ \\
\hline \multirow{2}{*}{ 7E } & Luar & $79,7 \mathrm{~dB}$ & $61,8 \mathrm{~dB}$ \\
\cline { 2 - 4 } & Dalam & $65,4 \mathrm{~dB}$ & $73,2 \mathrm{~dB}$ \\
\hline
\end{tabular}

Sumber: Hasil Analisis, 2014

Dari tabel 6 diatas dapat dilihat bahwa tingkat kebisingan yang terukur di luar kelas lantai 3 MTsN 1 Pontianak melebihi ambang batas kebisingan untuk sekolah dalam Keputusan Menteri Lingkungan Hidup no. Kep-48/MENLH/11/1996 yaitu sebesar 55 dB. Tingkat kebisingan tertinggi di luar kelas pada jam 06.30-09.00 WIB adalah pada kelas 7E. Hal ini disebabkan karena posisi kelas yang dekat dengan jalan raya dimana pada jam pagi arus lalu lintas cukup padat dan arah angin yang mengarah ke kelas tersebut sehingga menunjukan nilai 79,7 dB. Tingkat kebisingan tertinggi pada dalam kelas terukur di kelas 7D yaitu sebesar 77,2 dB pada jam 10.00-13.00 WIB. Hal ini lebih disebabkan karena faktor kebisingan dari siswa yang sedang belajar sebab kebisingan di luar kelas pada kelas tersebut cukup kecil sehingga pengaruh kebisingan dari lalu lintas tidak terlalu berpengaruh.

\section{6) ANALISIS KUESIONER TENTANG KEBISINGAN}

Berikut adalah hasil kuesioner tentang kebisingan yang diberikan kepada siswa MTsN 1 Pontianak. Persentase yang ditunjukkan pada tabel 7 berikut ini menunjukkan persentase jawaban positif dari siswa tersebut. 
Tabel 7. Hasil Kuesioner Mengenai Kebisingan

\begin{tabular}{|c|c|c|}
\hline No. & Pertanyaan & $\begin{array}{l}\text { Persentase } \\
\text { (\%) }\end{array}$ \\
\hline 1 & Siswa yang mengetahui definisi kebisingan & 57 \\
\hline 2 & Siswa yang merasa bising dengan kondisi di sekolah & 96 \\
\hline 3 & $\begin{array}{l}\text { Siswa yang terganggu akibat suara bising dari lalu lintas } \\
\text { di depan sekolah }\end{array}$ & 61 \\
\hline 4 & Siswa yang ingin mengurangi kebisingan di kelas & 92 \\
\hline 5 & Siswa yang ingin meninggalkan area bising & 82 \\
\hline 6 & Siswa yang ingin pindah ke kelas yang lebih tenang & 57 \\
\hline 7 & $\begin{array}{l}\text { Siswa yang merasa dengan kondisi bising yang ada } \\
\text { berpengaruh terhadap nilai dan prestasi adik dalam } \\
\text { belajar }\end{array}$ & 72 \\
\hline 8 & $\begin{array}{l}\text { Siswa yang merasa terganggu akibat suara bising dari } \\
\text { lalu lintas saat jam istirahat di luar kelas }\end{array}$ & 49 \\
\hline 9 & Siswa yang tahu bagaimana cara mengatasi kebisingan & 49 \\
\hline 10 & $\begin{array}{l}\text { Siswa yang tahu bahwa kebisingan dapat berdampak } \\
\text { buruk terhadap kesehatan }\end{array}$ & 47 \\
\hline
\end{tabular}

Sumber: Hasil Analisis Kuesioner, 2014

Dari tabel 7 dapat dilihat 96\% siswa menyatakan bahwa sekolah tersebut bising dan 61\% siswa menyadari kebisingan tersebut berasal dari lalu lintas yang berada di depan sekolah mereka sementara sisanya merasa terganggu tetapi tidak mengetahui sumber kebisingan itu berasal. Kemudian sebanyak $72 \%$ siswa menyatakan kondisi bising tersebut juga mempengaruhi nilai serta prestasi.

\section{7) ANALISIS KUESIONER TENTANG GANGGUAN KOMUNIKASI DAN KONSENTRASI BELAJAR}

Hasil kuesioner tentang gangguan komunikasi dan konsentrasi dapat dilihat pada tabel 8 berikut. 
Tabel 8. Hasil Kuesioner Mengenai Gangguan Komunikasi dan Konsentrasi

\begin{tabular}{|c|c|c|}
\hline No. & Pertanyaan & $\begin{array}{l}\text { Persentase } \\
\quad(\%)\end{array}$ \\
\hline 1 & $\begin{array}{l}\text { Siswa yang merasa terganggu dalam berkomunikasi } \\
\text { dengan teman sekelas akibat kebisingan }\end{array}$ & 81 \\
\hline 2 & $\begin{array}{l}\text { Siswa yang merasa kebisingan menganggu mereka } \\
\text { dalam mendengarkan penjelasan guru }\end{array}$ & 90 \\
\hline 3 & $\begin{array}{l}\text { Siswa yang merasa harus berteriak jika sedang berbicara } \\
\text { dengan teman saat di kelas akibat kebisingan }\end{array}$ & 81 \\
\hline 4 & $\begin{array}{l}\text { Siswa yang merasa akibat kebisingan tersebut teman } \\
\text { mereka harus berteriak jika sedang berbicara dengan } \\
\text { mereka }\end{array}$ & 83 \\
\hline 5 & $\begin{array}{l}\text { Siswa yang paham atau mengerti apa yang diucapkan } \\
\text { teman sekelas tanpa harus melihat dan memperhatikan } \\
\text { gerak bibirnya }\end{array}$ & 77 \\
\hline 6 & $\begin{array}{l}\text { Siswa yang pernah ditegur oleh teman sekelas akibat } \\
\text { mereka kurang memahami apa yang dibicarakannya di } \\
\text { kelas }\end{array}$ & 74 \\
\hline 7 & $\begin{array}{l}\text { Siswa yang menyatakan bahwa kebisingan tersebut } \\
\text { mengganggu konsentrasi belajar mereka }\end{array}$ & 89 \\
\hline 8 & $\begin{array}{l}\text { Siswa yang menyatakan bahwa kebisingan tersebut } \\
\text { mengganggu konsentrasi dalam membaca buku } \\
\text { pelajaran }\end{array}$ & 88 \\
\hline 9 & $\begin{array}{l}\text { Siswa yang merasa kebisingan tersebut membuat } \\
\text { mereka menjadi lebih mudah emosi atau marah }\end{array}$ & 72 \\
\hline
\end{tabular}

Sumber: Hasil Analisis Kuesioner, 2014

Dari tabel 8 diatas dapat disimpulkan bahwa lebih dari 70\% siswa mengalami gangguan komunikasi dan konsentrasi akibat kebisingan tersebut. Hal ini ditunjukkan sebanyak $81 \%$ siswa merasa terganggu dalam berkomunikasi dengan teman sekelas akibat kebisingan dan $90 \%$ merasa terganggu dalam mendengarkan penjelasan guru. Persentase siswa yang merasa terganggu konsentrasi dalam belajar akibat kebisingan sebesar $89 \%$. Hampir semua siswa mengalami gangguan komunikasi dan konsentrasi akibat kebisingan yang cukup tinggi di MTsN 1 Pontianak. Hal ini juga didukung oleh teori Kids dan Cit Geary (1998), kebisingan antara 55-65 dB, berdampak terhadap kesehatan jasmani siswa berupa kebisingan berdampak pada proses belajar mengajar di sekolah. Bising yang masuk di ruangan kelas mengakibatkan murid sulit mendengar dan berkonsentrasi terhadap pelajaran yang diberikan oleh guru.

\section{8) UPAYA MENGATASI KEBISINGAN DI MTsN 1 PONTIANAK}

Berdasarkan data diatas, kebisingan yang terdapat di MTsN 1 Pontianak sudah berada di atas ambang batas dan menyebabkan gangguan komunikasi dan konsentrasi terhadap siswa sekolah tersebut. Hal ini sebaiknya segera diatasi karena akibat gangguan tersebut kesehatan siswa juga dapat terganggu serta dapat menyebabkan menurunnya prestasi siswa. Upaya untuk mengurangi tingkat kebisingan akibat lalu lintas tersebut ada 4 cara yaitu : 
1. Penanggulangan kebisingan langsung ke sumber bising yaitu dengan membuat gundukan pada jalan (pita penggaduh), marka jalan dan rambu lalu lintas agar kendaraan mengurangi laju kendaraan saat melewati sekolah.

2. Penanggulangan kebisingan di bangunan sekolah yaitu dengan membuat barrier dalam bentuk pagar atau dinding yang lebih tinggi di depan sekolah sehingga kebisingan dapat tertahan dan dipantulkan. Juga penataan ruang kelas yang berada dekat dengan jalan raya agar dipindah ke lokasi yang agak jauh dari sumber bising. Serta memberikan bahan-bahan peredam bunyi pada ruang kelas sehingga suara bising tidak mengganggu proses belajar mengajar di dalam kelas.

3. Penanggulangan kebisingan di ruang kelas terdapat beberapa cara yaitu penambahan tirai atau gorden pada jendela dapat mengurangi tingkat kebisingan yang masuk. Pada pintu dapat ditambahkan unsur peredam suara pada bagian luar yang menghadap ke sumber kebisingan sehingga suara dari luar tidak masuk. Jika memungkinkan, mengganti material pintu kelas ke bahan yang lebih solid juga dapat mengurangi kebisingan. Memasang karpet pada lantai dan dinding kelas juga dapat menjadi alternatif penanggulangan kebisingan di dalam kelas.

4. Penanggulangan dengan menggunakan jalur hijau yaitu dengan menanam pohon di depan sekolah tersebut. Pohon dapat meredam suara dengan cara mengabsorpsi gelombang suara oleh daun, cabang, dan ranting. Jenis tumbuhan yang paling efektif untuk meredam suara adalah yang mempunyai tajuk tebal dengan daun yang rindang. Dedaunan tanaman dapat menyerap kebisingan sampai 95\%. Dengan menanam berbagai jenis tanaman dengan berbagai strata yang terdiri dari pohon dan semak atau perdu yang cukup rapat dan tinggi akan dapat mengurangi kebisingan, khususnya dari kebisingan yang sumbernya berasal dari bawah. Contoh jenis tanaman peredam kebisingan adalah Tanjung (Mimusops elengi), Kiara payung (Filicium decipiens), Tehtehan pangkas (Acalypha sp), Kembang Sepatu (Hibiscus rosa sinensis), Bougenvil (Bougenvillea $s p$ ) dan Oleander (Nerium oleander).

Diharapkan dengan langkah-langkah diatas dapat mengurangi tingkat kebisingan dan menanggulangi masalah gangguan konsentrasi yang dialami siswa MTsN1 Pontianak.

\section{KESIMPULAN}

1. Tingkat kebisingan di MTsN 1 Pontianak telah melebihi ambang baku mutu yaitu 55 dB.Tingkat kebisingan terbesar pada Jalan Alianyang adalah $74.2 \mathrm{~dB}$, sedangkan pada halaman sekolah sebesar 66,6 dB.

2. Tingkat kebisingan kelas yang murni berasal dari bising lalu lintas dan tidak dipengaruhi kebisingan dari siswa adalah pada pengukuran di luar kelas 7E dan 7F. Tingkat kebisingan yang tertinggi pada luar kelas $7 E$ adalah $79,7 \mathrm{~dB}$, sedangkan pada luar kelas $7 \mathrm{~F}$ sebesar 71,8 dB.

3. Dari analisis kuesioner, $96 \%$ siswa menyatakan bahwa sekolah tersebut bising, kemudian sebanyak $62,5 \%$ siswa menyatakan kondisi bising tersebut juga mempengaruhi nilai serta prestasi mereka. Kebisingan dari lalu lintas di depan sekolah mempengaruhi komunikasi dan konsentrasi siswa dimana ditunjukkan dengan $89 \%$ responden menyatakan kebisingan dari lalu lintas mengganggu konsentrasi mereka dalam proses belajar mengajar di kelas.

\section{UCAPAN TERIMA KASIH}

Dengan selesainya penelitian ini saya mengucapkan terima kasih yang sebesar-besarnya kepada Allah Swt, kedua orang tua, kedua dosen pembimbing yaitu Ibu Dian Rahayu Jati, ST, M.Si. dan Ibu S. Nurlaily Kadarini, ST, MT. serta kepada teman-teman Teknik Lingkungan 2010 dan semua orang yang telah berperan dalam membantu penelitian yang tidak dapat di ucapkan satu persatu. Harapan saya penelitian ini dapat bermanfaat bagi semua dan dapat dipergunakan sebagaimana mestinya. 


\section{DAFTAR PUSTAKA}

Ahmadi, Abu. 2003. Psikologi Umum. Rineka Citra. Jakarta

Cowan, J.P., 1994. Handbook of Environmental Accoustic. Van Nostrand Rainhold. New York

Doelle, Leslie L. 1993. Akustik Lingkungan. Erlangga. Jakarta

Departemen Kesehatan RI. 1995. Petunjuk Pelaksanaan Pengawasan Kebisingan. Departemen Kesehatan RI. Jakarta.

Departemen Pekerjaan Umum. 2005. Standar Nasional Indonesia (SNI) Pt-T-16-2005-B, Pedoman Perencanaan Teknik Bangunan Peredam Bising. Departemen Pekerjaan Umum. Jakarta

Dinas Perhubungan Komunikasi dan Informatika. 2012. Penyusunan Tataran Transportasi Lokal Kota Pontianak. Pontianak.

Djunaedi, E. 2003. Akustik Untuk Gedung Sekolah. Pikiran Rakyat. Jakarta

Griefhan B., Scheumer R., Moehler U., dan Mehnhert P. 2000. Physiological, subjective and behavioural responses during sleep to noise from rail and road traffic. Noise \& Health. Department of Environmental Health, Karolinska Hospital. Stockholm.

Hidayati, Nurul. 2007. Pengaruh Arus Lalu Lintas Terhadap Kebisingan. Universitas Muhammadiyah Surakarta. Surakarta.

Makmun, Abin. 2003. Psikologi Kependidikan. Remadja Rosdakarya Offset. Bandung

Mansyur, Muchtaruddin. 2003. Dampak Kebisingan Terhadap Kesehatan. Job Training Petugas Pengawas Kebisingan. Yogyakarta.

Michaud, D.S. 2005. Annoyance in Canada. Noise and Health. Department of Environmental Health, Karolinska Hospital. Stockholm.

Purnanta, M, Dkk. 2008. Pengaruh bising Terhadap Konsentrasi Belajar Murid Sekolah Dasar. Master Mini Dekade, Yogyakarta.

Soeripto. 1996. Berbagai Penyakit yang Ditimbulkan Akibat Kerja. Jakarta.

Tambunan, Sihar Tigor Benjamin. 2005. Kebisingan Di Tempat Kerja. ANDI, Yogyakarta. 